\title{
BMJ Open Breast cancer patients' return to work (B-CARE): protocol of a longitudinal mixed-methods study aiming to explore medical and occupational rehabilitation of patients with breast cancer in Germany
}

Kati Hiltrop (1) , ${ }^{1,2}$ Paula Heidkamp,,${ }^{1,2}$ Christoph Kowalski, ${ }^{3}$ Nicole Ernstmann ${ }^{1,2}$

To cite: Hiltrop K, Heidkamp P, Kowalski C, et al. Breast cancer patients' return to work (B-CARE): protocol of a longitudinal mixed-methods study aiming to explore medical and occupational rehabilitation of patients with breast cancer in Germany. BMJ Open 2019;9:e033533. doi:10.1136/ bmjopen-2019-033533

- Prepublication history for this paper is available online To view these files, please visit the journal online (http://dx.doi org/10.1136/bmjopen-2019033533).

Received 09 August 2019 Revised 14 November 2019 Accepted 15 November 2019

Check for updates

(c) Author(s) (or their employer(s)) 2019. Re-use permitted under CC BY-NC. No commercial re-use. See rights and permissions. Published by BMJ.

${ }^{1}$ Center for Health Communication and Health Services Research (CHSR), Department for Psychosomatic Medicine and Psychotherapy, University Hospital Bonn, Bonn, Germany

${ }^{2}$ Center for Integrated Oncology (CIO Bonn), University Hospital Bonn, Bonn, Germany

${ }^{3}$ German Cancer Society, Berlin, Germany

Correspondence to

Kati Hiltrop;

kati.hiltrop@ukbonn.de

\section{ABSTRACT}

Introduction In recent years, research has been done on determinants of return to work (RTW) in cancer survivors and their long-term work outcomes. Nevertheless, little is known about the survivors' evaluation of these outcomes in terms of job satisfaction and voluntariness. Hence, B-CARE aims at filling the research gap by providing a longitudinal cohort study investigating medical and occupational rehabilitation including an evaluation by breast cancer survivors.

Methods and analysis A mixed-methods approach, combining a quantitative survey with qualitative semistructured interviews, is used to study breast cancer survivors 5-6 years after diagnosis. These data will be linked to data from prior waves of patients during hospitalisation and 10 and 40 weeks after hospital discharge as well as routine data from the German Statutory Pension Insurance Scheme and German Cancer Society if available. The actual survey focuses on determinants of medical rehabilitation use, RTW, subsequent employment patterns post care as well as the voluntariness of and satisfaction with job changes. Ethics and dissemination A positive vote from the ethics committee of the Medical Faculty of the University of Bonn has been obtained. Data protection regulations will be adhered to for all handled data. Personal identifiers of participants will be pseudonymised. Dissemination strategies include a workshop to discuss results among stakeholders such as representatives of the German Statutory Pension Insurance Scheme, social workers and self-help groups.

Trial registration number German Clinical Trials Register (DRKS00016982); Pre-results.

\section{INTRODUCTION}

Breast cancer is the most common type of cancer among women, with around 70000 newly diagnosed cases per year in Germany. ${ }^{1}$ Around $30 \%$ of affected women are under 55 years of age. ${ }^{2}$ In combination with decreasing mortality rates due to therapeutic success
Strengths and limitations of this study

- First German study to investigate factors influencing the use of medical rehabilitation and return to work with patients from a representative sample of certified German breast cancer centres.

- Diverse data sources and plan to link primary data (survey and interview data) and secondary data (routine and certification data).

- Primary data allow for longitudinal analyses as they were collected at multiple time points, ranging from shortly after breast cancer diagnosis to the survival phase 5-6years later.

- Some measures could be affected by recall bias; however, all instruments will be pretested to check if participants are able to answer the questions.

- Due to the sample consisting of women with (breast) cancer, the results may not translate to men with (breast) cancer.

and early detection through screening programme, ${ }^{2}$ this makes successful medical and occupational rehabilitation to ensure patients' social participation after survival increasingly important.

Although patients with cancer in Germany are entitled to at least 3 weeks of inpatient rehabilitation after completing primary care, current numbers show that only around $60-70 \%$ of patients with breast cancer make use of this opportunity offered by the German Statutory Pension Insurance Scheme, ${ }^{3-5}$ and the rates are declining. ${ }^{6}$ The available research on barriers to the use of medical rehabilitation among patients with cancer is scarce. ${ }^{7}$ Its results suggest that barriers are diverse, ranging from personal, family-related and occupational reasons to system-related reasons. ${ }^{89}$ For example, being away from the 


\begin{tabular}{|l|l|}
\hline $\begin{array}{c}\text { (1) Quantitative data } \\
\text { - PIAT survey (T1, T2, T3) } \\
\text { - B-CARE survey (T4) }\end{array}$ & \multicolumn{1}{c|}{ (2) Qualitative data } \\
\hline \multicolumn{2}{|c|}{ (3) Routine data } \\
$\begin{array}{l}\text { B-CARE interviews (T4) } \\
\text { - Individual level data provided by } \\
\text { German Statuory Pension Insurance } \\
\text { Scheme }\end{array}$ & $\begin{array}{l}\text { - Organisational level data provided by } \\
\text { German Cancer Society }\end{array}$ \\
\hline
\end{tabular}

Figure 1 Data sources of the B-CARE project. PIAT, 'Strengthening patient competence: Breast cancer patients' information and training needs' study.

family, financial pressure to return to work soon, fear of exposure to other affected persons being a negative influence and a lack of outpatient rehabilitation options hinder cancer patients' use of rehabilitation. Cancer stage, age, psychological strain and information available on rehabilitation are considered to predict participation in medical rehabilitation. ${ }^{7}$ However, sociodemographic factors have a rather small predictive power regarding use of rehabilitation measures. ${ }^{10}$

Since it is supposed to enable occupational rehabilitation, medical rehabilitation is important for the growing number of patients with breast cancer of working age. That is why the German Statutory Pension Insurance Scheme offers a variety of measures to encourage patients' return to work (RTW) based on the 'rehabilitation before retirement' principle. ${ }^{11}$ Particularly in recent years attempts were made to intensify work-related content in medical rehabilitation. ${ }^{12}$ Still, RTW rates are comparatively low in Germany: while $80 \%$ of patients with breast cancer in the United States return to work, only $59 \%$ of them do so in Germany. ${ }^{13}$

To understand the RTW of cancer survivors, national and international studies conducted in recent years investigated its determinants and timing and found that disease, treatment and work related as well as sociodemographic and psychosocial factors influence RTW. ${ }^{14-19}$

In addition to initial RTW, studies investigated the occurrence of job changes, unemployment and other long-term work outcomes in cancer survivors up to 10 years post diagnosis. ${ }^{352021}$ Inter alia, it was found that perceived barriers to resuming work seem to change over time ${ }^{20}$ and that cancer survivors may suffer financial burdens due to reduced working hours 5 years post diagnosis. ${ }^{5}$

While long-term work outcomes have been analysed, little is known about how cancer survivors evaluate these outcomes in terms of job satisfaction and the voluntary nature of their employment development. ${ }^{22}$ Hence, more longitudinal studies exploring RTW, ${ }^{23}$ its long-term outcomes and their evaluation from the cancer survivors' perspective are needed, as work contributes to the social and psychological well-being of cancer survivors. ${ }^{21} 24$

\section{Aims of the study}

B-CARE aims at filling the research gap by providing a longitudinal cohort study investigating breast cancer survivors' rehabilitation use, RTW and subsequent employment patterns post care in Germany considering disease, treatment and work related as well as sociodemographic and psychosocial information using a mixed-methods approach. The results may contribute to the development of specific measures to increase the number of patients in medical rehabilitation and to have an understanding of cancer survivors' long-term workrelated needs.

\section{METHODS AND ANALYSIS}

\section{Study design}

B-CARE is a multicentre, non-interventional, mixedmethods cohort study combining several data sources, which are illustrated in figure 1. Quantitative survey data as well as qualitative data from semi-structured interviews will be used. Routine data on the individual and organisational level are intended to be included. The use of diverse data sources enables generating a holistic understanding of the research topic by balancing weaknesses and strengths of each individual data source, ${ }^{25}$ for example, eliminating possible biases based on selfreported measures by the addition of more objective routine data. The project will be conducted between May 2018 and December 2020.

\section{Recruitment \& Sample}

For 'Strengthening patient competence: Breast cancer patients' information and training needs' (PIAT) study, a representative sample of $n=1359$ patients with breast cancer was recruited in $n=60$ breast cancer centres throughout Germany in 2013/2014. The $n=60$ participating breast cancer centres were part of a random sample of $n=98$ German Cancer Society-certified breast cancer centres. Participants came from 15 out of 16 federal states in Germany. The breast cancer centres included all patients who had their initial breast cancer diagnosis and surgery between 1 February and 31 August 2013. Surveys were conducted at three time points: during hospitalisation, 10 weeks after hospital discharge and 40 weeks after hospital discharge (T1: $\mathrm{n}=1359$; T2: $\mathrm{n}=1248 ; \mathrm{T} 3$ : $\mathrm{n}=1202$ ). Further information on the recruitment and sampling of the PIAT study can be found in Schmidt $e t a l^{26}$

B-CARE is based on a subsample of the PIAT sample. The subsample includes $n=530$ patients with a breast cancer diagnosis (C50.x or D05.x) and sufficient German language skills who worked prior to this diagnosis and gave consent to be recontacted in case of a follow-up. B-CARE carries out this follow-up 5-6years after the patients' hospital discharge. The sample of $n=530$ possible participants will be invited by mail. Additionally, some of the survey participants who gave consent to be re-contacted will take part in a semi-structured interview (around $\mathrm{n}=30$ ). Participants will be selected through theoretical sampling aiming at maximising the heterogeneity of the sample. The sample shall vary with respect to sociodemographic factors (eg, age, number of children, marital status) and psychosocial factors (eg, health literacy) as 
Table 1 Central elements of the quantitative PIAT and BCARE questionnaires

\begin{tabular}{|c|c|c|c|c|}
\hline & $\begin{array}{l}\text { PIAT } \\
\text { T1 }\end{array}$ & $\begin{array}{l}\text { PIAT } \\
\text { T2 }\end{array}$ & $\begin{array}{l}\text { PIAT } \\
\text { T3 }\end{array}$ & $\begin{array}{l}\text { B- } \\
\text { CARE } \\
\text { T4 }\end{array}$ \\
\hline \multicolumn{5}{|c|}{ Disease and treatment-related variables } \\
\hline $\begin{array}{l}\text { Treatment process/after } \\
\text { care }\end{array}$ & $\mathrm{x}$ & $\mathrm{x}$ & $x$ & $x$ \\
\hline Comorbidities & $x$ & & & $x$ \\
\hline \multicolumn{5}{|l|}{ Psychosocial variables } \\
\hline (Psycho)social support & $x$ & $x$ & $x$ & $x$ \\
\hline Fear and depression & & & $x$ & $x$ \\
\hline Fear of progression & $x$ & & $x$ & $x$ \\
\hline Self-efficacy & & & & $x$ \\
\hline Health literacy & $x$ & $x$ & $x$ & $x$ \\
\hline Quality of life & & $x$ & $x$ & $x$ \\
\hline Coping & & & & $x$ \\
\hline \multicolumn{5}{|c|}{ Information needs and sources variables } \\
\hline $\begin{array}{l}\text { Information needs, } \\
\text { sources and use }\end{array}$ & $\mathrm{x}$ & $\mathrm{x}$ & $x$ & $x$ \\
\hline \multicolumn{5}{|c|}{ Rehabilitation-related variables } \\
\hline Medical rehabilitation use & & $x$ & $\mathrm{x}$ & $\mathrm{x}$ \\
\hline $\begin{array}{l}\text { Evaluation of medical } \\
\text { rehabilitation }\end{array}$ & & & & $x$ \\
\hline $\begin{array}{l}\text { Occupational } \\
\text { rehabilitation }\end{array}$ & & & $x$ & $x$ \\
\hline $\begin{array}{l}\text { Evaluation of occupational } \\
\text { rehabilitation }\end{array}$ & & & & $x$ \\
\hline $\begin{array}{l}\text { Sociodemographic } \\
\text { variables }\end{array}$ & $x$ & $\mathrm{x}$ & $\mathrm{x}$ & $\mathrm{x}$ \\
\hline
\end{tabular}

PIAT, 'Strengthening patient competence: Breast cancer patients' information and training needs' study.

well as based on rehabilitation process characteristics (use of medical rehabilitation, RTW process). Participants who give written consent and fill in the survey will be included in the study.

\section{Measures}

Quantitative data

The quantitative PIAT and B-CARE questionnaires consist of validated scales and self-developed measures. The selfdeveloped measures are in line with standards of survey question development. ${ }^{27}$ Table 1 illustrates the central contents of both questionnaires.

The PIAT questionnaire was designed to investigate information needs among recently diagnosed patients with breast cancer. The questionnaire included, among others, questions on participants' disease and course of treatment, measures of psychosocial and sociodemographic characteristics, and questions on information needs, sources and their use (eg, regarding treatment, support measures, financial issues).
The B-CARE questionnaire aims at measuring determinants of use of medical rehabilitation, RTW and subsequent employment patterns post care. Therefore, the questionnaire contains, inter alia, questions on the participants' aftercare, psychosocial and sociodemographic measures and questions on information needs, now focused on rehabilitation.

Disease and treatment-related variables include questions regarding the frequency and type of aftercare examinations, cancer recurrence and existing comorbidities. Psychosocial variables comprise questions on the need for and use of (psycho) social support as well as validated scales to measure fear and depression (HADS-D ${ }^{28}$ ), fear of progression $\left(\mathrm{PA}-\mathrm{F}-\mathrm{KF}^{29}\right)$, self-efficacy $\left(\mathrm{ASKU}^{30}\right)$, health literacy (HLS-EU-Q16 ${ }^{31}$ ), quality of life (EORTC QLQ$\left.\mathrm{C} 30,{ }^{32} \mathrm{SF}^{3} 6^{33}\right)$ and coping $\left(\mathrm{FKV}^{34}\right)$. Information needs and sources are assessed based on the CaPIN scale. ${ }^{35}$ Rehabilitation-related variables include questions on the frequency and evaluation of medical rehabilitation. With regard to occupational rehabilitation, patients may, among other things, be asked about their current work status, occurrence and timing of job changes, desirability of and satisfaction with changes as well as overall satisfaction with their employment development since surviving cancer. Sociodemographic variables cover sex, year of birth, first language, school-leaving qualification, vocational training, cohabitation with partner, marital status, number of children, number of children in the household, occupational status, main earner in the household and household income.

The outcome 'use of rehabilitation' is measured by the number of rehabilitation programme used because of participants' breast cancer since diagnosis. RTW is measured dichotomously. Additionally, the type and amount of work changes are assessed in combination with voluntariness and contentment.

\section{Qualitative data}

The qualitative interview guide contains open-ended stimulus questions, complemented by further narrativegenerating questions. ${ }^{36}$ These interviews provide the opportunity to analyse breast cancer patients' experiences with medical and occupational rehabilitation in a more detailed way than the quantitative survey. The aim is to investigate promoters and barriers to both medical and occupational rehabilitation as well as to create an understanding of job changes. Possible gaps and shortcomings regarding the long-term support of breast cancer survivors can be made visible. The interview guide covers questions on expectations and experiences regarding processes in medical and occupational rehabilitation as well as decision regret.

In order to assure the comprehensibility of all scales and measures used, cognitive pretests will be performed according to research standards, and adjustments will be made if necessary. ${ }^{37}$ Both the written questionnaire and the interview guide are developed with the help of existing literature and the input of an expert group 
including researchers as well as representatives of the German Statutory Pension Insurance Scheme, social workers and self-help groups.

\section{Routine data}

Individual routine data from the German Statutory Pension Insurance Scheme will be accessed for the purposes of matching with the survey and interview data if available. Routine data provide retrospective longitudinal information about the use and benefits of medical and vocational rehabilitation without the risk of recall bias. Routine data may cover the participants' employment pattern post care as well as applications for and use of rehabilitation measures.

\section{Certification data}

German Cancer Society certification data on the organisational level of breast cancer centres allow analyses on the impact of centres' structural characteristics on the use of rehabilitation measures and the RTW rate. Variables such as recommended and provided therapies, number of mastectomies or psycho-oncological support will be matched with patients' individual-level data.

\section{Data collection}

Persons will be contacted by mail and receive the study information, a consent form, a survey questionnaire to fill in at home and two stamped envelopes in which to return the documents to the research centre (the consent form and questionnaire are to be sent separately). Filling in the survey will take up to $60 \mathrm{~min}$. Before participating, patients will be informed about the study and asked to provide written consent for data collection and processing as well as pseudonymised analysis. In line with the Dillman's Total Design Method for surveys, two reminders will be sent in order to increase the response rate. ${ }^{38}$

For the qualitative interviews, participants will be chosen using theoretical sampling in order to increase the heterogeneity of the sample. ${ }^{39} 40$ They will be recontacted via mail or phone to set an appointment for the interview. The qualitative semi-structured interviews will be carried out via telephone or face-to-face. Face-to-face interviews will take place in the participants' preferred location (at home or at the research centre). The interviews will last no longer than $90 \mathrm{~min}$. All interviews will be documented by audio recordings and interviewers' memory protocols. ${ }^{39}$ Consent for audio recording and analysis of the pseudonymised data will be obtained from participants before the interview. Throughout the interviewing process, the interview guide may be altered in accordance with qualitative research standards. ${ }^{39}$ The sampling process will continue until theoretical saturation is reached, that is, to the point at which further cases will not generate more knowledge regarding the research topic. $^{40}$

The quantitative and qualitative data collection will run concurrently. $^{25}$

\section{Data analysis}

Quantitative data

The quantitative B-CARE survey data will be digitalised using the Teleform data capturing software and checked regarding plausibility. Data will be used according to the coding manuals after testing their psychometric properties. All personal data that allow identification will be deleted before merging data files and analysis. Therefore, the research team will match pseudonymised routine and survey data into one data set. This longitudinal data set will comprise quantitative data from PIAT (T1-T3), B-CARE (T4), if available routine data from the German Statutory Pension Insurance Scheme as well as aggregated certification data from the German Cancer Society on the breast cancer centres where participants were treated. Quantitative data will be analysed with the IBM SPSS V.25 statistical software. Multivariate and multilevel regression models will be estimated to investigate disease, treatment and work related as well as sociodemographic and psychosocial determinants of medical rehabilitation use and RTW as well as the subsequent employment patterns post care of cancer survivors under consideration of qualitative and quantitative data from hospitalisation until 5-6years post diagnosis.

\section{Qualitative data}

Audio records of the qualitative interview data will be transcribed verbatim and analysed using the grounded theory method. ${ }^{39}$ At least two researchers will analyse the data independently with the help of MAXQDA software. Categories will be derived from existing literature and complemented with categories based on the data in order to include all relevant aspects regarding the research issue. ${ }^{39} 40$ The data will be subsequently interpreted by a group of researchers.

\section{Triangulation}

All data sources will be matched to a mixed-methods data matrix in order to be able to comparatively analyse quantitative and qualitative findings. ${ }^{41}$ The matrix will be created so that each row represents data of one participant, while the columns contain quantitative and qualitative data collected for each case. This procedure allows studying (1) participants, taking into consideration different data types, as well as (2) patterns across different participants. $^{41}$

\section{Patient and public involvement statement}

Representatives of self-help groups and social workers are cooperation partners of the B-CARE project. Support will be received regarding the design of the study, development of instruments and discussion of results.

\section{ETHICS AND DISSEMINATION}

\section{Ethical considerations}

Data protection regulations will be adhered to for all handled data. While developing the data protection concept, special attention has been paid to ensure data 
security as data from several sources will be matched on an individual level. A positive vote of the ethics committee of the Medical Faculty of the University Bonn has been obtained.All participants will be informed about the study's procedure and aims, with study information being provided before participants give written consent to collect, save and analyse their pseudonymised data.

\section{Dissemination plan}

The results will be discussed in a workshop among stakeholders (German Statutory Pension Insurance Scheme, breast cancer centres, social workers and selfhelp groups). A results report for stakeholders will be prepared. In order to disseminate the findings among the health services research community, scientific publications and presentations on conferences are planned.

Acknowledgements The authors would like to thank all breast cancer survivors participating in the study as well as our cooperation partners.

Contributors All authors were involved in selecting the appropriate study design, data management and data protection standards and the data collection tools. $\mathrm{KH}$ drafted and revised all sections of the paper. PH, CK and NE revised the paper.

Funding This work was supported by a grant of the German Statutory Pension Insurance Scheme (Deutsche Rentenversicherung Bund, grant number 8011 - 106 - 31/31.128).

Competing interests CK is employed by the German Cancer Society (DKG). All other authors declare no conflicts of interest.

Patient consent for publication Not required.

Ethics approval A positive vote of the ethics committee of the Medical Faculty of the University Bonn has been obtained.

Provenance and peer review Not commissioned; externally peer reviewed.

Open access This is an open access article distributed in accordance with the Creative Commons Attribution Non Commercial (CC BY-NC 4.0) license, which permits others to distribute, remix, adapt, build upon this work non-commercially, and license their derivative works on different terms, provided the original work is properly cited, appropriate credit is given, any changes made indicated, and the use is non-commercial. See: http://creativecommons.org/licenses/by-nc/4.0/.

ORCID iD

Kati Hiltrop http://orcid.org/0000-0002-8357-0855

\section{REFERENCES}

1 Robert Koch-Institut. Bericht zum Krebsgeschehen in Deutschland 2016 [Report on cancer in Germany 2016]. Berlin, Germany; 2016.

2 Robert Koch-Institut, Gesellschaft der epidemiologischen Krebsregister in Deutschland e.V. Krebs in Deutschland für2013/2014 [Cancer in Germany for 2013/2014]. Berlin, Germany, 2017.

3 Noeres D, Park-Simon T-W, Grabow J, et al. Return to work after treatment for primary breast cancer over a 6 -year period: results from a prospective study comparing patients with the general population. Support Care Cancer 2013;21:1901-9.

4 Kowalski C, Heuser C, Halbach S, et al. Inanspruchnahme vonRehabilitationsleistungen bei Patientinnen mit Brustkrebs [Use of rehabiliation services among patients with breast cancer] [abstract]. In: 17th Deutscher Kongress für Versorgungsforschung (DKVF. Berlin, Germany: German Medical ScienceGMS Publishing House, 2018.

5 Arndt V, Koch-Gallenkamp L, Bertram H, et al. Return to work after cancer. A multi-regional population-based study from Germany. Acta Oncol 2019;58:811-8.

6 Deutsche Rentenversicherung Bund. Reha-Bericht 2018. Die medizinische und berufliche Rehabilitation der Rentenversicherung im Licht der Statistik [Rehabilitation report 2018. Medical and occupational rehabilitation of the pension insurance in the light of statistics]. Berlin, Germany; 2018.

7 Deck R, Babaev V, Katalinic A. Gründe für die Nichtinanspruchnahme einer onkologischen Rehabilitation. Ergebnisse einer schriftlichen Befragung von Patienten aus onkologischen Versorgungszentren
[Reasons for the Non-Utilisation of an Oncological Rehabilitation. Results of a Written Survey with Patients of Oncological Healthcare Centers]. Rehabilitation 2019;58.

8 Deck R, Walther AL. Warum gehen onkologische Reha-Anträge und Reha-Leistungen der Deutschen Rentenversicherung zurück? Ergebnisse qualitativer Interviews mit Patienten aus onkologischen Versorgungszentren [Are there Social Inequalities in the Utilisation of Oncological Rehabilitation by Breast Cancer Patients? Results of qualitative interviews with patients of oncological supply centers]. $P R$ 2017;29:76-83.

9 Miedema B, Easley J. Barriers to rehabilitative care for young breast cancer survivors: a qualitative understanding. Support Care Cancer 2012;20:1193-201.

10 Geyer S, Schlanstedt-Jahn U. Gibt es soziale Ungleichheiten in der Inanspruchnahme der onkologischen Rehabilitation be Mammakarzinompatientinnen [Are there Social Inequalities in the Utilisation of Oncological Rehabilitation by Breast Cancer Patients]? Gesundheitswesen 2012;74:71-8.

11 Deutsche Rentenversicherung Bund. Erwerbsminderungsrenten [Reduced-earning-capacity-pensions]. Available: https://www. deutsche-rentenversicherung.de/DRV/DE/Rente/AllgemeineInformationen/Rentenarten-und-Leistungen/Erwerbsminderung srente/erwerbsminderungsrente_node.html [Accessed 1 Dec 2019].

12 Bethge M. Rehabilitation und Teilhabe am Arbeitsleben [Rehabilitation and work participation]. Bundesgesundheitsblatt Gesundheitsforschung Gesundheitsschutz 2017;60:427-35.

13 Rick O, Kalusche E-M, Dauelsberg T, et al. Reintegrating cancer patients into the workplace. Dtsch Arztebl Int 2012;109:702-8.

14 Mehnert A. Employment and work-related issues in cancer survivors. Crit Rev Oncol Hematol 2011;77:109-30.

15 van Muijen P, Weevers NLEC, Snels IAK, et al. Predictors of return to work and employment in cancer survivors: a systematic review. Eur $J$ Cancer Care 2013;22:144-60.

16 Islam T, Dahlui M, Majid HA, et al. Factors associated with return to work of breast cancer survivors: a systematic review. BMC Public Health 2014;14(Suppl 3):S8.

17 Kiasuwa Mbengi R, Otter R, Mortelmans K, et al. Barriers and opportunities for return-to-work of cancer survivors: time for actionrapid review and expert consultation. Syst Rev 2016;5:35.

18 Sun Y, Shigaki CL, Armer JM. Return to work among breast cancer survivors: a literature review. Support Care Cancer 2017;25:709-18.

19 Paltrinieri S, Fugazzaro S, Bertozzi L, et al. Return to work in European cancer survivors: a systematic review. Support Care Cancer 2018;26:2983-94.

20 van Maarschalkerweerd PEA, Schaapveld M, Paalman $\mathrm{CH}$, et al. Changes in employment status, barriers to, and facilitators of (return to) work in breast cancer survivors $5-10$ years after diagnosis. Disabil Rehabil 2019;11:1-7.

21 Moran JR, Short PF, Hollenbeak CS. Long-term employment effects of surviving cancer. J Health Econ 2011;30:505-14.

22 Mehnert A, de Boer A, Feuerstein M. Employment challenges for cancer survivors. Cancer 2013;119(Suppl 11):2151-9.

23 Heuser C, Halbach S, Kowalski C, et al. Sociodemographic and disease-related determinants of return to work among women with breast cancer: a German longitudinal cohort study. BMC Health Serv Res 2018;18:1000.

24 Peteet JR. Cancer and the meaning of work. Gen Hosp Psychiatry 2000;22:200-5.

25 Klassen AC, Creswell J, Plano Clark VL, et al. Best practices in mixed methods for quality of life research. Qual Life Res 2012;21:377-80.

26 Schmidt A, Wesselmann S, Kowalski C. Informationsbedürfnisse und Informationsprozesse in zertifizierten Zentren. Beispiel Brustkrebszentren - Ergebnisse der PIAT-Studie [Information needs and information processes in certified centers. Example breast cancer centers - results of the PIAT study]. Forum 2015;30:218-23.

27 Fowler FJ. Improving survey questions: design and evaluation. Thousand Oaks: Sage Publ, 1995.

28 Herrmann-Lingen C, Buss U, Snaith RP. Hospital Anxiety and Depression Scale - Deutsche Version (HADS-D): Manual [Hospital Anxiety and Depression Scale - German Version (HADS-D): Manual]. Bern: Hans Huber, 1995.

29 Mehnert A, Herschbach P, Berg P, et al. Progredienzangst bei Brustkrebspatientinnen - Validierung der Kurzform des Progredienzangstfragebogens PA-F-KF [Fear of progression in breast cancer patients - validation of the short form of the Fear of Progression Questionnaire (FoP-Q-SF)]. Zeitschrift für Psychosomatische Medizin und Psychotherapie 2006;52:274-88.

30 Beierlein C, Kemper CJ, Kovaleva A, et al. Kurzskala zur Erfassung allgemeiner Selbstwirksamkeitserwartungen (ASKU) [Short Scale for Measuring General Self-efficacy Beliefs (ASKU)]. Methoden, Daten, Analysen 2013;7:251-78. 
31 Sørensen K, Van den Broucke S, Pelikan JM, et al. Measuring health literacy in populations: illuminating the design and development process of the European health literacy survey questionnaire (HLSEU-Q). BMC Public Health 2013;13:948.

32 European Organisation for Research and Treatment of Cancer. EORTC QLQ-C30. Available: https://qol.eortc.org/ [Accessed 11 Oct 2019].

33 Bullinger M, Kirchberger I, Ware J. Der deutsche SF-36 Health Survey. Übersetzung und psychometrische Testung eines krankheitsübergreifenden Instruments zur Erfassung der gesundheitsbezogenen Lebensqualität [The German SF-36 Health Survey. Translation and Psychometric Testing of a Generic Instrument for the Assessment of Health-Related Quality of Life]. J Public Health 1995;3:21-36.

34 Muthny FA. Freiburger Fragebogen zur Krankheitsverarbeitung, FKV: Manual [Freiburg Questionnaire of Coping with IIIness, FQCl: Manual]. Weinheim: Beltz Test GmbH, 1989.

35 Neumann M, Wirtz M, Ernstmann N, et al. Identifying and predicting subgroups of information needs among cancer patients: an initial study using latent class analysis. Support Care Cancer 2011;19:1197-209.

36 Helfferich C. Die Qualität qualitativer Daten: Manual für die Durchführung qualitativer Interviews [The quality of qualitative data: Manual for conducting qualitative interviews]. 4th edn. Wiesbaden: VS Verlag für Sozialwissenschaften / Springer Fachmedien Wiesbaden GmbH Wiesbaden, 2011.

37 Lenzner T, Neuert C, Otto W. Cognitive Pretesting: GESIS survey guidelines. Mannheim GESIS Leibniz Institute for the Social Sciences, Germany; 2016.

38 Dillman DA. Mail and telephone surveys: the total design method. New York: Wiley, 1978

39 Strauss AL, Corbin JM. Grounded Theory: Grundlagen Qualitativer Sozialforschung [Grounded theory: Basics of qualitative social research]. Weinheim: Beltz Psychologie Verlags Union, 1996.

40 Flick U. An introduction to qualitative research. 5th edn. Los Angeles, Calif: Sage, 2014.

41 O'Cathain A, Murphy E, Nicholl J. Three techniques for integrating data in mixed methods studies. BMJ 2010;341:c4587. 